\title{
EPISTEMOLOGIA DE GASTON BACHELARD
}

EPISTEMOLOGY OF GASTON BACHELARD

\author{
Edilson Araújo do Nascimento \\ Universidade Estadual de Mato Grosso do Sul - UEMS \\ edilson_araujonascimento@hotmail.com
}

\begin{abstract}
Resumo
O presente artigo tem como objetivo principal levantar nas produções acadêmicas algumas das principais características da teórica do epistemólogo Gaston Bachelard. Para tanto, o corpus deste artigo é formado pelas produções acadêmicas obtidas através de levantamentos na Biblioteca Digital Brasileira de Teses e Dissertações - BDTD, repositório digital renomado, bem como em artigos apresentados na disciplina Teorias da Aprendizagem da Pós-Graduação em Educação Científica e Matemática da Universidade Estadual de Mato Grosso do Sul - UEMS e algumas das obras de Bachelard. Concluímos que a teoria de Bachelard embora não esteja totalmente voltada para a educação é importante para a compreensão da construção do conhecimento científico e ao mesmo tempo abre novos caminhos para conhecer o subconsciente humano.

Palavras-chave: Gaston Bachelard, Epistemologia, Revisão teórica.
\end{abstract}

\begin{abstract}
The present article has as main objective to raise in academic productions some of the main characteristics of the theory of the epistemologist Gaston Bachelard. To this end, the corpus of this article is formed by academic productions obtained through surveys at the Brazilian Digital Library of Theses and Dissertations - BDTD, a renowned digital repository, as well as in articles presented in the discipline Theories of Learning of Graduate Studies in Science and Mathematics Education from the State University of Mato Grosso do Sul - UEMS and some of Bachelard's works. We conclude that Bachelard's theory, although not totally focused on education, is important for the understanding of the construction of scientific knowledge and at the same time opens new ways to know the human subconscious.
\end{abstract}

Keywords: Gaston Bachelard, Epistemology, Theoretical Review.

\section{INTRODUÇÃO}

Gaston Bachelard, filósofo e poeta francês, suas ideias partem de uma filosofia das ciências naturais, especialmente a física, contribuindo para uma epistemologia que também utiliza métodos da psicanálise.

Melo (2005, p. 45) afirma que Bachelard "[...] foi um dos primeiros filósofos contemporâneos a tecer críticas acerca da imagem tradicional da ciência, a visão 
empírico-indutivista". Dessa maneira, a autora considera que as teorias de Bachelard propõem reflexões acerca do tratamento dado à ciência, visto que ela é um corpo complexo de conhecimento que não se dá por meio de um reducionismo ou mesmo de empirismo indutivista como vem sendo tratado nos ambientes de aprendizagem.

Dutra (2015, p. 28) colabora dizendo que Bachelard:

Em sua epistemologia, tece duras críticas ao ensino de Ciências, principalmente ao seu aspecto determinista, linear e comunicador de verdades prontas. Critica o modelo de ensino fundamentado na transmissão de conhecimentos prontos, ou seja, critica o modelo de educação bancária, centrada na passividade do estudante.

O autor afirma que na epistemologia de Bachelard é possível observar críticas ao ensino de Ciências que não considera a complexidade envolvida nesse processo e não aprova o modelo de ensino fundamentado na transmissão de conhecimentos prontos, como é o atual modelo de ensino utilizado pelas escolas.

Yamazaki (2011, p. 56) afirma que para Bachelard:

[...] a Ciência é uma construção complexa, longe do senso comum, não podendo, esta última, compreender por justaposição toda uma série de leis abstratas construídas historicamente. Esta forma de situar a ciência como um sistema demasiadamente complexo quando comparado com as observações e experiências do senso comum, incluindo os experimentos do Laboratório Didático, vem de um profundo estudo das leis que regem as Ciências.

Segundo Yamazaki (2011) é preciso compreender que a Ciência é uma construção complexa, como aponta Bachelard, sendo assim não deve ser confundida com o senso comum. Estudar ciências é muito mais que aplicar leis abstratas que foram construídas historicamente, sendo necessário um estudo profundo para compreender como se faz e ensina ciências.

Este trabalho busca apontar as principais características da epistemologia de Gaston Bachelard sem a pretensão de esgotar sua teoria, visto que sua obra é vasta e não caberia apenas neste artigo. Nosso intuito principal é desvelar as contribuições que a teoria bachelardiana pode trazer para o contexto escolar, tornando-se um caminho para compreensão do conhecimento científico e os obstáculos encontrados em sua evolução.

\section{PROCEDIMENTOS METODOLÓGICOS}

Para este artigo optamos por levantar produções acadêmicas em nível de dissertações de mestrados publicadas na Biblioteca Digital Brasileira de Teses e 
Dissertações (BDTD), em artigos apresentados na disciplina Teorias da Aprendizagem da Pós-Graduação em Educação Científica e Matemática da Universidade Estadual de Mato Grosso do Sul - UEMS e também em algumas das obras traduzidas de Bachelard.

Ferreira (2002, p. 258) afirma que as pesquisas bibliográficas objetivam:

[...] responder que aspectos e dimensões vêm sendo destacados e privilegiados em diferentes épocas e lugares, de que formas e em que condições têm sido produzidas certas dissertações de mestrado, teses de doutorado, publicações em periódicos e comunicações em anais de eventos.

Como já dito, além dos artigos apresentados na disciplina de Teorias da Aprendizagem da Pós-Graduação em Educação Científica e Matemática e algumas das obras de Bachelard, optouse pesquisar as dissertações que versam sobre os aspectos principais da epistemologia de Bachelard. Como estratégia de busca dessas produções acadêmicas foi realizada pesquisas na internet no site da BDTD através da palavra-chave "Bachelard" na titulação dessas dissertações. Através da busca foram obtidas 18 dissertações e entre essas cinco foram selecionadas por destacarem mais as teorias de Bachelard, assim essas dissertações passaram a formar o corpus da pesquisa juntamente com os artigos da disciplina de Teorias da Aprendizagem e algumas das obras de Bachelard.

Com o corpus já selecionado passou-se a buscar nele os elementos principais da vida e obra de Gaston Bachelard, traçando assim alguns pontos fundamentais de sua epistemologia e as contribuições para o ensino. Tais elementos serão expostos nos tópicos que veremos a seguir.

\section{A VIDA E A OBRA DE BACHELARD}

Gaston Bachelard nasceu em 27 de junho de 1884 em um vilarejo do interior da França denominado Bar-sur-Aube e morreu em 16 de outubro de 1962. Trabalhou na administração dos Correios e Telégrafos, sua função era pesar cartas, trabalho este que contribuiu para seus estudos posteriores. Formou-se em matemática, mas atuou também como professor de ciências, filosofia e história em universidades de Dijon e Sorbonne.

Bachelard dedicou parte de sua vida à educação básica, embora não tenha nenhuma obra específica voltada para a dimensão escolar, suas obras versam para o espírito científico e os devaneios poéticos. A leitura de Bachelard apresenta duas características marcantes: o Bachelard diurno e Bachelard noturno, o primeiro relacionado com a questão científica, ou seja, o saber científico relacionado com a razão e o segundo envolvendo questões poéticas, com a criação artística e os devaneios. Publicou 
obras importantes como "A formação do espírito científico", "A Filosofia do Não", "A epistemologia", entre outras.

No campo da filosofia discutiu o reducionismo e o caráter unitário das ciências, buscava fazer uma ciência da própria ciência. Bachelard apontou para a existência de obstáculos epistemológicos, onde os problemas do conhecimento deveriam ser encarados como obstáculos. Melo (2005) afirma que os obstáculos epistemológicos são definidos por Bachelard como sendo as dificuldades encontradas no movimento de construção do conhecimento.

Carvalho (2007, p. 65) afirma que para Bachelard:

[...] o progresso científico significa a superação de obstáculos epistemológicos, no contínuo processo de retificação de erros. Entre experiência cotidiana e verdades científicas, deve-se necessariamente instaurar uma ruptura epistemológica - visando a superação dos obstáculos representados por opiniões, hábitos e dogmas, que influenciam o cientista na pesquisa, apresentando-se como preconceitos, emoções ou hábitos culturais.

Carvalho (2007) aponta que na perspectiva de Bachelard o progresso científico somente ocorre quando há rupturas no conhecimento existente, ou seja, é preciso uma reorganização daquilo que se sabe para permitir que o novo conhecimento possa acrescentar no conceito presente no cognitivo do aprendiz. Isso muitas vezes causa desconforto, tornando o novo conhecimento um obstáculo, o que ele chama de obstáculos epistemológicos.

\section{NOÇÕES DE OBSTÁCULOS EPISTEMOLÓGICOS SEGUNDO BACHELARD}

Na epistemologia bachelardiana para aprender são necessárias mudanças culturais e racionais imprescindíveis ao aprendizado científico. Bachelard (1996, p.23) afirma que:

[...] o adolescente entra na aula de física com conhecimentos empíricos já constituídos: não se trata, portanto, de adquirir uma cultura experimental, mas sim de mudar de cultura experimental, de derrubar os obstáculos já sedimentados pela vida cotidiana.

Bachelard (1996) propõe uma ruptura com a cultura experimental sedimentada na vida cotidiana dos estudantes, ou seja, mudar a forma como esses veem a ciência, uma vez que fazer ciência é muito mais que realizar simples experimento. Entretanto, romper com esses obstáculos sedimentados pela vida cotidiana desses alunos e um grande desafio a ser enfrentado.

Silva (2015, p. 29) afirma que: 
A razão acomodada ao que já conhece, procura manter a continuidade do conhecimento, opondo-se à retificação dos erros ao introduzir analogias, metáforas e imagens no próprio ato de conhecer, com o fim de tornar familiar todo conhecimento abstrato, constituindo, assim, obstáculos epistemológicos. Tais obstáculos são identificados como epistemológicos, pois surgem no próprio ato de conhecer, numa relação entre o sujeito e o objeto do conhecimento.

Silva (2015) refere-se aos obstáculos epistemológicos de Bachelard como problemas no ato de conhecer, em sua visão o sujeito diante de um novo conhecimento tende a buscar familiaridade com aquilo que conhece o que pode tornar um obstáculo quando o sujeito não admite estar equivocado e busca no conhecimento enraizado familiaridade com esse novo conhecimento.

O obstáculo está na não aceitação do novo conhecimento e que são necessárias rupturas no que sabe oportunizando assim um novo olhar, dando a este um caráter novo, ou melhor, um caráter científico. Logo, Bachelard vai denominar obstáculos epistemológicos por esses surgirem no próprio ato de conhecer da relação do sujeito e o objeto do conhecimento.

Yamazaki (2011, p.51) "[...] as experiências pelas quais todos nós estamos sujeitos durante a vida são acomodadas em forma de sensações, valores, preconceitos que surtirão como obstáculos epistemológicos para a aceitação do conhecimento científico.".

Para o autor todas as experiências pelas quais passamos durante a vida se tornaram obstáculos epistemológicos para aceitação do conhecimento científico. Isso ocorrer porque o sujeito ao longo de sua vida vai conhecendo o objeto e dando a ele conceitos informais no ato de conhecer que por muito tempo, não havendo algo que contrária isto, torna tais conceitos verdadeiros. E no momento em que um "novo conhecimento" acerca deste objeto é posto diante do sujeito, ele impõe resistência em aceitá-lo, o que Bachelard vai denominar de obstáculo epistemológico.

Bachelard (1971, p. 165) afirma que:

Quando se procuram as condições psicológicas dos progressos da ciência, em breve se chega à convicção de que é em termos de obstáculos que deve pôr o problema do conhecimento científico. E não se trata de considerar obstáculos externos, como a complexidade e a fugacidade dos fenômenos, nem tão pouco de incriminar a fraqueza dos sentidos e do espírito humano: é no próprio acto de conhecer, intimamente, que aparecem, por uma espécie de necessidade funcional, lentidões e perturbações. É aqui que residem causas de estagnação e mesmo de regressão, é aqui que iremos descobrir causas de inércia a que chamaremos obstáculos epistemológicos. 
Bachelard (1996) denomina obstáculos epistemológicos como a inércia provocada por perturbações no próprio ato de conhecer, mesmo ele reconhecendo que o conhecimento científico avança por meio de obstáculos. Porém, para ele os obstáculos precisam ser superados para que o conhecimento científico possa avançar, caso contrário, residirá na estagnação ou mesmo a regressão.

Araújo (2017, p. 35) destaca que os obstáculos epistemológicos propostos por Bachelard estão presentes em sua obra "A formação do espirito científico" sendo eles "[...] a experiência primeira, o conhecimento geral, o obstáculo verbal, o substancialismo, o conhecimento unitário e pragmático, o obstáculo animista e o obstáculo ao conhecimento quantitativo.".

Colombo Junior (2010, p. 58) afirma que as experiências primeiras e o realismo ingênuo são vistas por Bachelard como sendo "[...] a experiência colocada antes e acima da crítica, o início dos obstáculos na formação do espírito científico." Ou seja, este obstáculo acaba sendo o resultado de uma atividade pouco pensada, que aborda fenômenos complexos como se fossem simples.

Acerca desse primeiro obstáculo Bachelard (1996, p. 29) afirma que "Já que a crítica não pôde intervir de modo explícito, a experiência primeira não constitui, de forma alguma, uma base segura.". Com isso o autor sustenta que na formação de um espírito científico não havendo crítica sobre as primeiras impressões torna-se um obstáculo para o avanço científico.

Ramos e Scarinci (2013, p. 13) colaboram afirmando que:

[...] experiência primeira, está relacionada ao fato das pessoas tentarem compreender o real a partir de um fato dado e imediato, sem procurarem racionalizar tal fato. Isso se deve a uma falta de reflexão teórica resultada por um deslumbramento dos indivíduos pelo objeto observado.

Ramos e Scarinci (2013) afirmam que o obstáculo experiência primeira está relacionado com a maneira que o sujeito busca compreender o real de forma imediatista, sem utilizar-se da razão, sem ao menos fazer uma reflexão teórica deste, ou seja, usa-se de um realismo ingênuo.

Yamazaki (2011, p. 54) referindo-se a epistemologia de Bachelard afirma que:

[...] em sua epistemologia, ele defende o que chama de catarse intelectual, ou seja, o levantamento dessas primeiras impressões, imagens primeiras sob as quais nos detemos e nos tornamos vulneráveis e inseguros. Ao descobrir o velho, tendemos a uma correção, abrindo a possibilidade de aprender o novo. É 
perseguindo uma ruptura entre o velho e o novo conhecimento, entre a observação primeira e a experimentação, que a formação científica deve caminhar.

Esse autor afirma que Bachelard propõe uma libertação intelectual, ou seja, é necessário que as primeiras impressões sejam abandonadas possibilitando a descoberta do novo conhecimento e somente através de rupturas entre o velho e novo conhecimento é que se constitui a formação de um espírito científico.

Ramos e Scarinci (2013, p. 13-14) afirmam que o segundo obstáculo denominado por Bachelard como conhecimento geral é:

[...] aquele que busca explicar todos os fenômenos a partir de uma lei ou conceito geral. No entanto, quando buscamos entender determinado fato por generalizações, essas, ao invés de ajudarem, acabam por imobilizar o pensamento e o desenvolvimento científico.

Para essas autoras o conhecimento geral proposto por Bachelard é algo que imobiliza a formação do espírito científico, isso porque ele tenta explicar todos os fenômenos através de uma lei ou um conceito geral.

Bachelard (1996, p. 90) afirma que:

O conhecimento a que falta precisão, ou melhor, o conhecimento que não é apresentado junto com as condições de sua determinação precisa, não é conhecimento científico. O conhecimento geral é quase fatalmente conhecimento vago.

Bachelard (1996) tece críticas com a forma como tenta generalizar conhecimento científico para ele essa maneira de minimizar o conhecimento é quase que fatal porque o torna impreciso. Além disso, afirmar que o conhecimento que não apresenta as condições de sua determinação não pode ser considerado conhecimento científico.

Ramos e Scarinci (2013, p. 14) afirma que o obstáculo verbal é:

[...] quando uma única palavra ou imagem é usada para construir toda a explicação. Quando o indivíduo carrega essas imagens e faz articulações entre palavras e imagens com suas funções, ele passa a conhecer metáforas da realidade e não a realidade propriamente dita.

As autoras apresentam o obstáculo verbal proposto por Bachelard como aquele em que o sujeito busca por meio de imagens ou palavras construir toda a explicação de um fenômeno, o que para Bachelard torna se um obstáculo na formação do conhecimento científico por apresentar metáforas da realidade, ou seja, uma falsa explicação.

Sobre o obstáculo substancialismo Bachelard (1996, p. 121) afirma que:

O obstáculo substancialista, como todos os obstáculos epistemológicos, é 
polimorfo. É constituído por intuições muito dispersas e até opostas. Por uma tendência quase natural, o espírito pré-científico condensa num objeto todos os conhecimentos em que esse objeto desempenha um papel, sem se preocupar com a hierarquia dos papéis empíricos. [...] Mas, ainda uma vez, tais distinções levariam ao esquecimento do aspecto vago e infinitamente tolerante da substancialização, ao descuido com o movimento epistemológico que é alternado, do interior para o exterior das substâncias, prevalecendo-se da experiência externa evidente, mas escapando à crítica pelo mergulho na intimidade.

Com isso Bachelard (1996) propõe que a substancialização pode atrapalhar o avanço do pensamento científico porque permite aos sujeitos uma explicação temporária e decisiva.

Silva (2015) apresenta o obstáculo substancialismo de Bachelard como àquele que relaciona a possibilidade de atribuir qualidades diversas e ocultas a uma determinada substância, ou mesmo fazer corresponder a toda qualidade uma substância.

Com relação ao obstáculo unitário e pragmático, Silva (2015) afirma ser um obstáculo causado por uma tentativa de solucionar problemas no conhecimento científíco através de uma visão geral de mundo, ou mesmo por simples princípio geral da natureza. E o obstáculo pragmático leva a induções e generalizações amplas e de caráter fillosófico.

Sobre o obstáculo unitário e pragmático Bachelard (1996, p. 117) afirma que:

\begin{abstract}
A necessidade de generalização extrema, às vezes por um único conceito, leva a idéias sintéticas que conservam o poder de seduzir. Todavia, em nossos dias, uma certa prudência retém o espírito científico. Restam apenas filósofos que procuram - senão a pedra filosofal - a idéia filosofal que explique o mundo.
\end{abstract}

Bachelard compreende o poder da sedução que as generalizações, porém, alerta para o fato de que muitas vezes tais generalizações requerem prudência para que venham a ser obstáculo na formação do espírito científico.

Silva (2015) afirma que o obstáculo animista proposto por Bachelard é aquele que possuí uma tendência de conferir vida a objetos inanimados, ou seja, consiste na introdução do conceito de "vida" em um campo distinto daquele das ciências biológicas.

Batista (2006) refere-se aos obstáculos epistemológicos de Bachelard como sendo aqueles que "[...] devem ser superados para que se consiga formar e estabelecer uma mentalidade científica significativa". Logo, o conhecimento somente terá um caráter científico quando os obstáculos que o cercam são superados. É através da superação destes obstáculos que o pensamento é direcionado para uma crescente coerência racional, 
onde Bachelard irá caracterizar através de uma hierarquia as zonas de um perfil epistemológico, que veremos no tópico seguinte.

\section{A EVOLUÇÃO FILOSÓFICA DO CONHECIMENTO E A NOÇÃO DO PERFIL EPISTEMOLÓGICO}

A evolução filosófica do conhecimento científico caminha sempre em direção de uma maior racionalidade e nesse sentido Colombo Junior (2010, p. 70) afirma que para Bachelard:

[...] a evolução (desenvolvimento) de conceito que vai desde um pensamento realista ingênuo, passando pelo positivismo (empirismo), racionalismo clássico (que segundo o autor ganha toda sua clareza no final do século XVII com Newton), até pensamentos mais sofisticados chamados pelo autor de ultraracionalismo.

Colombo Junior (2010) compreende que na visão de Bachelard a evolução epistemológica do conhecimento científico ocorre com a passagem de quatro fases: realismo ingênuo, empirismo, racionalismo clássico e ultra-racionalismo. Bachelard ilustrou seu pensamento realizando o seu próprio perfil epistemológico relacionados com os conceitos de massa e energia, mas optaremos por não o apresentar neste artigo, porém, faremos uma breve explanação de cada uma destas etapas.

A primeira etapa proposta por Bachelard, o realismo ingênuo, é definida por Ramos e Scarinci $(2013$, p.14) como sendo "[...] as opiniões primeiras, o senso comum e muitas das concepções alternativas que as pessoas desenvolvem, independente de suas formações escolares, e o fato de que o real existe a priori e não é uma construção humana".

As autoras afirmam que o realismo ingênuo é marcado pela falta de teorias para conhecer o objeto de estudo, ou seja, o sujeito se deixa levar pelas impressões pessoais, pelo senso comum e pelas concepções alternativas que tem acerca do objeto, em suma nesta fase do conhecimento a teoria ainda não foi incorporada no ato de conhecer.

Já o empirismo, segundo estágio na evolução filosófica do conhecimento, o conceito deixa para trás o senso comum e começa a ser formulado a partir de experiências simples e manipulações do objeto do conhecimento. No entanto, os métodos empiristas são baseados no vazio teórico, correndo o risco do pesquisador se deixar enganar por aquilo que lhe é visível e ter uma falsa impressão da verdade e não se 
aprofundar no conceito de científico.

A terceira doutrina filosófica apontada por Bachelard na evolução do conhecimento é o racionalismo clássico, sobre isso Colombo Junior (2010, p. 71) afirma que é a fase onde "[...] estabelecem-se relações claramente racionais, analisadas por leis racionais da aritmética". O autor sugere que nessa fase a razão prevalece sobre o real em que o conceito científico é obtido diante de aproximações mediadas pela teoria.

A quarta e última doutrina filosófica é o ultra-racionalismo que para Bachelard funciona como o alargamento do conhecimento é nesta etapa que se tem o conceito complexo do objeto do conhecimento.

A noção do perfil epistemológico do sujeito se dá após percorrer estas quatro etapas da evolução filosófico do conhecimento. O sujeito pode em determinados conceitos científicos estar estagnados em uma destas doutrinas filosóficas e isto sugere que um mesmo conceito pode não estar em uma mesma etapa para todos, ou seja, há perfis epistemológicos diferentes para um mesmo conceito.

\section{CONSIDERAÇÕES}

O propósito deste artigo inicialmente era de realizar algumas características acerca das teorias do filósofo e epistemológico francês Gaston Bachelard, buscando analisar à luz de outros autores alguns pontos principais de sua teoria, principalmente sobre a ideia de obstáculos epistemológicos, evolução filosófica do conhecimento e também da noção do perfil epistemológico. O intuito deste trabalho não foi esgotar toda a teoria de Bachelard, até porque não seria possível uma vez que sua obra é vasta e precisaria de maior estudo e aprofundamentos.

Por meio deste artigo foi possível compreender que Bachelard em sua teoria apresenta a evolução do conhecimento por meio de rupturas com os conhecimentos já enraizados na mente dos sujeitos e que muitas vezes tais rupturas sofrem resistências a mudanças, o que Bachelard irá denominar de obstáculos epistemológicos. Bachelard ainda propõe que a evolução do conhecimento ocorre somente quando o sujeito é capaz de transpor estes obstáculos. É preciso compreender que alguns conceitos por estarem enraizados no cognitivo dos sujeitos provocam maior resistência à mudança e em algum momento poderão retornar caso não haja uma ruptura bem sucedida. 
O filósofo francês em sua teoria destaca que a evolução filosófica do conhecimento ocorre após o percurso de quatro etapas, que foram elucidadas na parte final deste artigo. Bachelard ainda propõe que o conceito de ciências ou o ensino de ciências seja mais bem explorado pelos docentes, pois a ciência vai muita além de se fazer experimentos simples como é habitualmente realizado nas escolas. Ele condena ato de experimentar, mas é preciso ter clareza para não passar uma falsa impressão aos discentes de que ciências são somente experimentos simples.

Concluímos que a teoria de Bachelard pode ser aplicada no contexto escolar para compreender os fatores que impossibilitam a construção ou avanço conhecimento científico. Mesmo não tendo direcionado suas obras para a dimensão escolar é possível identificar na teoria de Bachelard caminhos para compreender melhor a construção do conhecimento e os fatores que impedem sua evolução. Desta maneira, este artigo cumpre seu objetivo que é de trazer a teoria de Gaston Bachelard como uma alternativa viável no contexto escolar.

\section{REFERÊNCIAS BIBLIOGRÁFICAS}

ARAÚJO, David Velanes de. A noção de ruptura epistemológica no pensamento de Gaston Bachelard. Salvador, 2017. Dissertação (Mestrado) - Programa de PósGraduação em Filosofia, Universidade Federal da Bahia.

BACHELARD, Gaston. A epistemologia. Tradução de Fátima Lourenço Godinho e Mário Carmino Oliveira. Portugal: Editora 70, 2006.

BACHELARD, Gaston. A formação do espírito científico. Tradução de Estela dos Santos Abreu. Rio de Janeiro: Contraponto Editora, 1996.

BATISTA, Thiago Guimarães. A Pedagogia Implícita em "A formação do Espírito Científico", de Gaston Bachelard. Fortaleza, 2006. Dissertação (Mestrado em Filosofia) - Programa de Pós-Graduação em Filosofia, Universidade Federal do Ceará.

CARVALHO, Marcelo José. O devaneio cósmico e o conhecimento de si: Gaston Bachelard da alma poética à androginia da alma. Rio de Janeiro. 2007. Dissertação (Mestrado em Filosofia) - Programa de Pós-Graduação em Filosofia, Universidade do Estado do Rio de Janeiro.

COLOMBO JUNIOR, Pedro Donizete. Uma percepção da gravidade em espaço fisicamente modificado: uma análise à luz de Gaston Bachelard. São Paulo, 2010. Dissertação (Mestrado em Ensino de Ciências) - Programa de Pós-Graduação Interunidades em Ensino de Ciências, Universidade de São Paulo.

DUTRA, José Ciriaco. Uma proposta para ensino de física centrada na história da ciência e epistemologia de Bachelard. Bagé, 2015. Dissertação (Mestrado em Ensino de 
Ciências) - Programa de Pós-Graduação em Ensino de Ciências, Universidade Federal do Pampa.

FERREIRA, Norma Sandra de Almeida. As pesquisas denominadas "estado da arte". Educação \& Sociedade, Campinas, V.23, n.79, ago. 2002, p. 258.

MELO, Ana Carolina Staub de. Contribuições da epistemologia histórica de Bachelard no estudo da evolução dos conceitos de óptica. Florianópolis. 2005. Dissertação (Mestrado em Educação Científica e Tecnológica) - Programa de PósGraduação em Educação Científica e Tecnológica, Universidade Federal de Santa Catarina.

RAMOS, Tacita Ansanello; SCARINCI, Anne L. Análise de concepções de tempo e espaço entre estudantes do ensino médio, segundo a epistemologia de Gaston Bachelard. Revista Brasileira de Pesquisa em Educação em Ciências (RBPEC). ISSN 1806-5104. p. 9- 25. Vol 13. n 2, 2013.

SILVA, Jackson Kamphorst. Uma proposta de ensino de tópicos de mecânica quântica sob a ótica de Bachelard. Bagé, 2015. Dissertação (Mestrado em Ensino de Ciências) - Programa de Pós-Graduação em Ensino de Ciências, Fundação Universidade Federal do Pampa.

YAMAZAKI, Sérgio Choiti; YAMAZAKI, Regiani Magalhães de Oliveira. Pressupostos bachelardianos em sala de aula. In: GONÇALVES, A. V.; PINHEIRO, A. S.; FERRO, M. E. (Orgs.). Estágio Supervisionado e Práticas Educativas. Dourados/MS: Editora UEMS, 2011. p.49-74. 